\title{
Can Working Memory Strategies Enhance English Vocabulary Learning?*
}

\section{¿Pueden las estrategias para entrenar la memoria de trabajo mejorar el aprendizaje de vocabulario en inglés?}

\author{
Diana Ibarra Santacruz \\ dianais@udenar.edu.co \\ Universidad de Nariño, Pasto, Colombia \\ David Martínez Ortega \\ dsmartinez@umariana.edu.co \\ Universidad Mariana, Pasto, Colombia
}

This study sought to determine how working memory training could contribute to retaining vocabulary studied in English lessons through the implementation of a set of strategies. Two intact groups of beginners: one experimental, with 28 students, and one control group, with 22 students, belonging to undergraduate English as a foreign language courses at a Colombian university were involved in the study. After being exposed to a series of memory strategies for a period of 10 weeks, it was evident that most learners in the experimental group benefited from the intervention and showed gradual progress in the retention and retrieval of the words studied in the lessons; thus, improving their overall competence in the foreign language.

Key words: English language learning, memory strategies, vocabulary retention, working memory.

This study is based on a master's thesis presented by one of the authors (Martínez Ortega, 2016) to obtain the degree of MA in teaching English as a foreign language from Universidad ICESI (Colombia).

Received: September 12, 2017. Accepted: February 24, 2018.

How to cite this article (APA 6th ed.):

Ibarra Santacruz, D., \& Martínez Ortega, D. (2018). Can working memory strategies enhance English vocabulary learning? HOW, 25(2), 29-47. https://doi.org/10.19183/how.25.2.410.

This article is licensed under a Creative Commons Attribution-NonCommercial-NoDerivatives 4.0 International License. License Deed can be consulted at https://creativecommons.org/licenses/by-nc-nd/4.0/. 
Este estudio tuvo como objetivo determinar cómo el entrenamiento de la memoria de trabajo puede contribuir a retener el vocabulario en inglés estudiado en clase a través de la implementación de algunas estrategias diseñadas para ejercitar este tipo de memoria. Dos grupos intactos de estudiantes en nivel básico: uno experimental, con 28 estudiantes, y otro de control, con 22 estudiantes, pertenecientes a los cursos de inglés como lengua extranjera ofrecidos en pregrado en una universidad colombiana hicieron parte de este estudio. Después de un periodo de 10 semanas, se evidenció que la mayoría de los estudiantes que recibieron la intervención mostraron mejora en su habilidad para memorizar y recordar el vocabulario estudiado en la clase, lo cual a su vez fortaleció su competencia el idioma extranjero.

Palabras clave: aprendizaje del inglés, estrategias de memorización, memoria de trabajo, retención de vocabulario.

\section{Introduction}

In the language learning process, there are a number of factors, both cognitive and affective, that intervene and may play a determining role in how successfully this process is carried out; one of these, without a doubt, is memory. Memory is that complex mental workplace where information of all sorts and sources is stored, processed, and retrieved in order to accomplish an endless number of tasks. There are three main types of memory: long-term, short-term, and working memory (WM); each one of them is in charge of specific functions, but it is the last type that has proved to be particularly associated with how effectively a language is learned. A large body of research (Atkins \& Baddeley, 1998; Daneman \& Hannon, 2007; Ellis \& Sinclair, 1996; Engel de Abreu \& Gathercole, 2012; Martin \& Ellis, 2012) has demonstrated that WM capacity is crucial for the completion of classroom activities, and it is also evident that such capacity varies from one person to another, accounting for differences in learning achievement. Likewise, there exist various views supporting the idea that WM can actually be trained; hence, increasing its capacity to retain and process the information required for effective language learning to take place (Chein \& Morrison, 2010; Gathercole \& Alloway, 2007; McNamara \& Scott, 2001). On the basis of these grounds, this research intended to determine if it is possible to boost vocabulary learning by incorporating a number of WM training strategies into English language lessons. The results of this study may serve as a basis to make educated choices that can potentially optimize the language learning process.

\section{Literature Review}

Learning is generally defined as the acquisition of knowledge or skills as a result of experience (Cell as cited in Jarvis, 2006), but such acquisition can only take place when we are able to store information through a mechanism called memory, which basically allows the individual to retain and retrieve information over time. There were initially two types of 
memory identified: long-term and short-term memory; however, Baddeley and Hitch (1974), who have extensively studied the memory system, later put forward a model of short-term storage, whose bond with long-term storage comprises a more active function than just storing. It was then that the concept of WM started to be used and deemed to be a useful workplace wherein complex cognitive activities engage.

\section{Working Memory}

In general terms, WM is defined as a system for temporary storage and control of information necessary for a wide range of complex cognitive activities (Baddeley, 2003). In the same way, Shenfield (2012) states that WM is the faculty to mentally maintain previously learned or newly acquired information for a short period of time and use it in problem solving and task completion. This concept of WM is what constitutes Baddeley and Hitch's model (1974), which has had great influence in the field of cognitive psychology and has transcended to language learning. The model presented by Baddeley and Hitch originally consisted of three components: two short-term stores and a control system, explained as follows:

Phonological loop. It is described as a storage system for speech-based information, responsible for storing, manipulating and retaining aural material over a short period of time. This component is divided into two sub constituents: (a) The phonological store, which holds speech material for brief intervals; and (b) the articulatory rehearsal mechanism, which is used to mentally recite the information in the phonological store. This process is used to increase the capacity of phonological short-term memory and to prevent the information from being lost by refreshing it (Baddeley \& Hitch, 1974).

The visuospatial sketchpad. It is the storage system responsible for briefly holding visual and spatial material and can be employed when thinking, remembering, and processing tasks. Within the visuospatial sketchpad, it is possible to remember the visual features of an object and the place where the object is located in space (Baddeley \& Hitch, 1974).

The central executive. This component is responsible for determining when and where information is delivered, either in the phonological loop for verbal information or the visuospatial sketchpad for visual. It is also assumed to be responsible of focusing, dividing, switching attention, and linking WM to long-term memory (Baddeley, 2000; Baddeley \& Hitch, 1974). Additionally, this component is deemed crucial in connecting the WM system to higher-order language abilities such as language comprehension (Cain, Oakhill, \& Bryant; Seigneuric, Ehrlich, Oakhill, \& Yuill as cited in Engel de Abreu \& Gathercole, 2012).

Although the former WM model was very successful in experimental research, it was criticized for the lack of evidence explaining the link between long-term knowledge and WM. 
Accordingly, a fourth constituent to the model was introduced: the episodic buffer (Baddeley, 2000). This fourth component is a limited capacity storage system with several functions, such as the possibility to combine information from different sources (verbal and visual) into episodes, manipulate information, modify it, and ultimately link it to the knowledge stored in the individual's long-term memory.

Given the particularities of the WM system, and being this a mechanism involved in the preservation of information while simultaneously engaged in a task, it is believed that individuals vary widely in the amount of information they can hold accessible, namely WM capacity, which affects their performance in diverse cognitive tasks. This capacity and the extent to which it interferes with learning processes, including language, has been the focus of a wide number of studies as explained next.

\section{Working Memory and Second Language Acquisition}

Since WM plays a decisive role in complex cognitive processes, it is considered to be one of the most critical components of linguistic achievement. In the same way, it is believed that individuals with larger working memory capacity are better able to learn vocabulary (in both first and second languages), write better, and have better foreign language (L2) reading and listening comprehension (Atkins \& Baddeley, 1998; Daneman \& Hannon, 2007). A number of studies in the area have tackled the relationship between WM capacity (measured by complex span tasks, digit, word, reading span tasks, among others) and L2 performance. Harrington and Sawyer (1992), for instance, found a positive correlation between participants' reading spans in L2 and their performance in the grammar and reading sections of the TOEFL; that is, subjects with larger WM capacity scored higher on measures of reading skill. Similarly, Service (1992) examined the acquisition of English as a second language by Finnish children, finding that children with good WM capacity proved to be better at language learning than those with limited capacity, not only in terms of vocabulary, but also syntax. In the same line, Kormos and Sáfár (2008) found a connection between phonological short-term memory capacity and the overall proficiency of pre-intermediate learners, and between the digit span test and the L2 acquisition of learners at a beginner's level of proficiency. Likewise, Martin and Ellis (2012) examined the incidence of WM and phonological loop on vocabulary and grammar learning of an artificial language without explicit instruction. The researchers reported positive correlations between WM capacity and the participants' ability to translate to and from a new lexicon.

Research addressing the role of the phonological loop in L2 learning has also taken place during the last decades. For instance, Ellis and Sinclair (1996) studied Welsh adult learners and discovered that those who repeated the language aloud had better performance on vocabulary learning. It was demonstrated that the more L2 structures are rehearsed, 
the easier it is to learn them and generalize rules from them. Additionally, Engel de Abreu and Gathercole (2012) state that due to the particularities of the phonological loop, that is, storage capacity and rehearsal mechanism, it may play a key role- especially at early stages of vocabulary learning, which is subsequently facilitated by knowledge stored in the learner's long-term memory. Supporting this view, Ellis (1996, 2012, and 2013) argues that the entire phonological loop component may be involved in chunking and consolidating a series of constructions at different linguistic levels (e.g., phonemes, lexis, formulaic sequences, and morphosyntactic constructions) into the long-term memory system. In the same line, Alharbi (2015) states that mentally repeating new words as we hear them may activate the phonological loop, increasing the chances to store them and subsequently retrieve them.

The above is a very brief review of some of the most relevant studies regarding the link between WM and language learning, and the findings suggest a clear correlation between the two. If this connection is as strong as it is claimed to be, it would have further implications in the field of second language acquisition (SLA) as it may account for different levels of proficiency among learners.

\section{Working Memory Problems and Learning Difficulties}

As discussed earlier, there exists empirical evidence supporting the idea that WM is associated with one's ability to perform cognitive tasks in various areas. In classroom settings, Gathercole and Alloway (2007) explain that there are numerous indicators of limited WM capacity in learners, for instance, distraction, rapid loss of information, and difficulties to mentally process material and remember information. Limitations in WM together with individual differences may hinder the learning process, making it difficult for learners to remember or make inferences about new information encountered while reading, access knowledge from long-term memory, and integrate new information with knowledge from long-term memory. It is also common among students with WM difficulties to hear teachers' directions and instructions, but this load of information overwhelms their WM system and so it is partially or completely lost. Therefore, they are unable to complete classroom tasks and achieve course objectives. In the field of SLA, Daneman and Merickle (1996) claim that learners with WM limitations are unlikely to integrate information, find a pronoun's referent, monitor for semantic inconsistencies between texts, resolve lexical ambiguity, abstract a main theme, make comparisons, struggle to remember new vocabulary or grammar rules, and do well on general comprehension. Overall, learners with limited WM would experience difficulties in mastering the different skills and components of the language, which would ultimately affect the development of other higher order skills.

It is clear that WM capacity varies from one individual to another, and reasons behind this disparity are still not conclusive. On the one hand, Engle, Kane, and Tuholski (1999) 
claim "individual differences on measures of WM capacity primarily reflect differences in capability for controlled processing" (p. 104). Holmes (2012), on the other hand, asserts that there is a limit to the amount of information individuals can hold accessible in their WM to be later manipulated. Conversely, McNamara and Scott (2001) state that an individual's WM limitations are a result of the individual's lack of strategies to process information. These are three different views on the source of WM problems; however, they all point to the idea that such problems may be overcome by means of targeted training as will be described in the next section.

\section{Strategies That Boost Working Memory Capacity}

Given the mounting evidence on the intervention of WM in the cognitive processes such as language learning, numerous paradigms suggesting that WM can be directly trained have also emerged. Among them, we have core training, which involves repetition of demanding WM tasks with varied stimuli aimed to improve multiple components of the WM system. Some of the most well-known core-training programs are COGITO, which comprises perceptual speed, and episodic memory tasks, and Cogmed, ${ }^{1}$ which involves various tasks including backward digit span, location memory, tracking of moving visual objects, among others (Chein \& Morrison, 2010). A second paradigm is strategy training, which involves teaching diverse tactics to encode, maintain, and retrieve information from WM. This approach aims to improve performance in tasks requiring retention of information for a period of time (Chein \& Morrison, 2010). Some examples of strategy training include chunking (St ClairThompson, Stevens, Hunt, \& Bolder as cited in Chein \& Morrison, 2010), creating a story with the information to be remembered (McNamara \& Scott, 2001), and using imagery to make items more salient (Carretti et al. as cited in Chein \& Morrison, 2010).

A third paradigm has to do with the idea that teachers need to adapt their teaching approach in such a way that those learners who may have WM limitations can better process the information and avoid having memory overload (Gathercole \& Alloway, 2007; Holmes, 2012). Even though this is a different approach, it goes hand-in-hand with the idea that working memory can be enhanced by targeted training. Gathercole and Alloway (2007) put forward a series of strategies that fit into this paradigm and are described as follows:

1. Monitoring the student. It is vital to look for warning signs of memory overload and also to estimate the WM demands of the task.

2. Reduce the memory load. Break tasks and instructions down into smaller steps. If possible, assign one task at a time, keep directions brief and straightforward, and repeat them for the learners if needed.

In 2010, Cogmed was purchased by Pearson Education (see https://en.wikipedia.org/wiki/Cogmed). 
3. Repeat and review. It can be done by using visual prompts of the steps, by providing opportunities to repeat the task, or by having students practice class contents in short sessions during the day rather than in one long session.

4. Advance organizers. Teaching students how to use organizers such as "what I know, what I want to know, and what I learned"; (KWL) charts can be beneficial as they trigger prior knowledge, help generate questions, and assist students to connect new knowledge to what they already know.

5. Encourage the use of memory aids. Teachers should provide instructions through written material such as handouts, whiteboard or slices of paper. Conversely, they could encourage students to create posters of frequently used words.

6. Pause, paraphrase, summarize, and allow time. It is always necessary to stop the lesson and ask students for a quick summary followed by notes on the board. Also, students will probably remember more if they hear their own voices or a classmate's voice.

7. Color code. Coding with consistent colors can help students memorize information more effectively. Teachers can try to color code new concepts and sentence structure; for instance, nouns can be red, verbs can be green, and adjectives blue.

8. Key words. Try to train learners to grasp central words in a listening task. Those learners with WM deficits generally need more time to answer questions; therefore, providing them with cues to help them focus on the correct words can be helpful.

9. Reinforce learning preferences. Modern software programs can be an effective alternative to rehearsing and interiorizing information from the lessons by encouraging students to define what worked best for them.

Since the strategies proposed by Gathercole and Alloway (2007) can indeed be incorporated into regular language lessons and do not need major adjustments from the teacher or the classroom setting, they were chosen to be applied in this study along with others addressed to activate the phonological loop. The aim was to determine if their application could enhance vocabulary learning among learners who display signals of WM problems.

\section{Method}

\section{Research Question}

Several studies have been conducted concerning WM capacity and its incidence in various cognitive tasks; one of the processes clearly affected by the extent of this capacity is second 
language learning. In this sense, empirical evidence suggests that individuals with larger working memory capacity are better able to learn vocabulary, write better, and have better L2 reading and listening comprehension skills unlike those with limited working memory, who display difficulties in retaining, processing, and retrieving information when needed; however, research findings also suggest that WM can be trained to counteract such difficulties and improve learning processes. In this regard, this action research study intended to find out if the implementation of WM strategies could enhance English vocabulary learning.

\section{Participants}

Fifty undergraduate students majoring in areas such as medicine, engineering, arts, international trade, psychology, law, and philosophy took part in this study. The subjects belonged to two different groups of English level II (elementary) in which they registered at the beginning of the semester after passing English level I with 96 hours of instruction, a course they were assigned after taking an institutional placement test. One of the groups, with 28 students, was selected as the experimental group, and the other, with 22 students, as the control group. The participants were young adults who had similar socio-economic backgrounds they were expected to have a basic command of the English language. It was necessary to work with these two intact groups for they were assigned to us at the beginning of the semester as part of our workload.

\section{Context}

This study was developed with two intact groups of undergraduate students taking English level II courses as a requirement for graduation at a Colombian public university. They are required to receive six hours of instruction a week divided in two sessions of three hours each and each course level lasts a total of 16 weeks. As for the lessons, these are mostly conducted considering the tenets of communicative language teaching (CLT) and other communicative approaches, such as task-based language teaching (TBLT) and cooperative language learning (CLL). Depending on the number of courses students are required to take, they are expected to achieve from basic to intermediate command of English.

\section{Type of Research and Research Design}

As stated previously, the main objective of the study was to find out if the participants in the experimental group would benefit from the implementation of a series of WM strategies in terms of vocabulary learning. To meet this objective, it was necessary to apply a pre-test and post-test in order to establish if there was a difference between the experimental and control group. The characteristics of this study fit into a quantitative type of research, which according to Mackey and Gass (2005), "generally starts with an experimental design in which 
a hypothesis is followed by the quantification of data and some sort of numerical analysis is carried out" (p. 2). In addition, this study is verification and outcome oriented, going in line with other features that are very particular of quantitative research. In terms of design, this study was deemed quasi-experimental, that is, participants were not randomly assigned to the experimental or control group (Cook \& Campbell, 1979); instead, it was necessary to work with intact classes, which were assigned to us at the beginning of the semester.

\section{Instruments}

The first instrument was a test designed to assess learners' vocabulary knowledge before and post intervention with the set of WM boosting strategies. The administration of this test and its results allowed us to determine the effectiveness of the strategies chosen to train and possibly enhance WM capacity oriented to L2 vocabulary learning. This instrument consisted of three tasks. In Task 1, students were asked to read attentively a text called The Wright brothers: Men with a vision by drawing their attention to how the irregular past forms in English language are formed. Then, they were given a series of gapped sentences to be filled in with a suitable verb from the previous text, whose objective was that they notice how past tense forms are correctly used in sentences. Finally, this task demanded a global understanding of the entire text by checking students' capacity to state whether some facts and information about the text were true or false and provide a brief explanation. Task 2 demanded from students similar procedures to those found in Task 1 . The reading was called Robert Goddard: An Incredible Man and it drew their attention to how the regular past forms in the English language are formed and work within a written composition. After carefully reading the text, they were asked to fill in some gaps with the past forms of some verbs from a chart found in the text. Lastly, they were required to unscramble some words and come up with correct sentences paying attention to grammar and meaning. These sentences were extracted from the text used in Task 1. Finally, Task 3 required students to move to the speaking and listening components. They worked in small groups and each student was assigned a role-play card containing information related to the previous tasks. One of the roles was, for example, being one of the Wright brothers, or being a journalist who had to interview the Wright brothers. In this way, they were prompted to use the past simple verbs studied earlier. The task was assessed in terms of the students' ability to incorporate the set of verbs into their utterances and also their accuracy.

The second instrument used for data collection was a checklist used to identify indicators of poor or strong WM capacity such as task completion, task engagement, instructions understanding, attention span, listening comprehension, reading comprehension (if applicable), access to previous knowledge, comprehension of new vocabulary, and remembering procedures. These checklists were filled out by us after the implementation of each of the tasks featured earlier in the test and were completed depending on the modality 
of the tasks, that is, individually or per group. However, as these checklists were intended to determine poor or strong WM indicators, their results will not be addressed in this paper due to the objective of this particular study, but they could be used for further analysis and discussion.

The last and probably the core instrument used with the experimental group were the memory training strategies which consisted of 10 tasks designed to tackle vocabulary learning around the topics to be covered throughout the course. The details of each of the tasks and their scoring criteria will be addressed in the following section.

\section{Procedure}

Two weeks after starting the course, the pre-test was administered in both the experimental and control groups. That being done, the lessons in the experimental group started to incorporate the WM boosting strategies (Gathercole \& Alloway, 2007, see Appendix), one per week, over a period of 10 weeks.

After the 10-week period, the performance of both the experimental and control group was assessed using a post-test which consisted of the same tasks implemented in the pre-test.

The three tasks designed for the pre-test were assessed individually, both in the experimental and control group, in terms of performance according to the following criteria: (a) Successful: when the task was completed with no apparent problems, (b) Acceptable: when the learner displayed some problems and inaccuracies in task completion, (c) Fair: when the student displayed major problems and partially completed the task, and (d) Poor: The student was unable to complete the task. It is worth noting that both successful and acceptable performances were considered as positive indicators of vocabulary knowledge in the pre-test or learning in the post-test as they suggest that there was task completion with minor or no difficulties; for that reason, the two criteria were grouped. Fair and poor performances, on the other hand, were both analyzed as negative indicators as they imply lack of task completion.

Finally, the results from the pre- and post-tests were analyzed quantitatively using independent-samples t-tests, which would provide statistical evidence of the extent of the difference in terms of performance between the experimental and control groups.

To do so, it was necessary to code the data by giving each performance criterion a number on a scale (successful $=4$, acceptable $=3$, fair $=2$, poor $=1$ ). The number of students was then distributed among the four different criteria based on their performance; that was done for each task. Subsequently, the number of students per criterion across tasks was averaged to be able to run the t-test. 


\section{Results}

Table 1 indicates the number of students from both the control and experimental groups and their corresponding performances across tasks in the pre-test, and it also shows the average number of students per performance criterion. At first glance, it is clear that the number of students with successful and acceptable performances was higher in the experimental group than in the control group across tasks. However, it is also seen that most students from both groups had fair and poor performances in the three tasks.

Table 1. Pre-Test Results From Experimental and Control Groups

\begin{tabular}{|l|l|c|c|c|c|}
\hline \multirow{2}{*}{ Performance } & \multicolumn{2}{|c|}{ Number of students } & \multirow{2}{*}{$\begin{array}{c}\text { Average No. } \\
\text { of students }\end{array}$} \\
\cline { 3 - 6 } & Task 1 & Task 2 & Task 3 & Taccessful \\
& Suntrol Group & 5 & 4 & 6 & 5 \\
\cline { 2 - 6 } & Acceptable & 0 & 0 & 2 & 1 \\
\cline { 2 - 6 } & Fair & 5 & 3 & 4 & 4 \\
\cline { 2 - 6 } & Poor & 12 & 15 & 10 & 12 \\
\hline \multirow{5}{*}{ Experimental Group } & Successful & 6 & 5 & 5 & 5 \\
\cline { 2 - 6 } & Acceptable & 4 & 3 & 8 & 5 \\
\cline { 2 - 6 } & Fair & 9 & 6 & 5 & 7 \\
\cline { 2 - 6 } & Poor & 9 & 14 & 10 & 11 \\
\hline
\end{tabular}

The results of the t-test (Table 2) revealed that the difference in terms of performance was not statistically significant between the control $(M=1.955, S D=1.253)$ and experimental $(M=2.143, S D=1.145)$ groups, $t(48)=-0.5538, p=0.58$, implying that the initial conditions were fairy similar as measured with the pre-test.

Table 2. T-test Results From Data Collected in Pre-Test

From Experimental and Control Groups

\begin{tabular}{|l|c|c|c|c|c|c|c|}
\hline \multicolumn{1}{|c|}{ Variable } & Observations & $\begin{array}{c}\text { Obs. with } \\
\text { missing } \\
\text { data }\end{array}$ & $\begin{array}{c}\text { Obs. } \\
\text { without } \\
\text { missing } \\
\text { data }\end{array}$ & Minimum & Maximum & Mean & SD \\
\hline Control & 22 & 0 & 22 & 1.000 & 4.000 & 1.955 & 1.253 \\
\hline Experimental & 28 & 0 & 28 & 1.000 & 4.000 & 2.143 & 1.145 \\
\hline
\end{tabular}

$t=-0.5538$

$d f=48$

$p$-value $=0.5823$ 
After implementing the different WM strategies, the post-test was applied. Table 3 shows the results obtained from the experimental and control groups across tasks in the posttest; these clearly indicate that the majority of students in the experimental group displayed mostly successful performance across tasks. As for the control group, most of the students had successful and acceptable performances only in Task 1; the vast majority performed poorly in Task 2, and a rather equal number of students obtained successful, fair, and poor performances in Task 3.

Table 3. Post-Test Results From Experimental and Control Groups

\begin{tabular}{|c|c|c|c|c|c|}
\hline & \multirow{2}{*}{ Performance } & \multicolumn{3}{|c|}{ Number of students } & \multirow{2}{*}{$\begin{array}{l}\text { Average No. } \\
\text { of students }\end{array}$} \\
\hline & & Task 1 & Task 2 & Task 3 & \\
\hline \multirow{4}{*}{ Control Group } & Successful & 11 & 3 & 8 & 8 \\
\hline & Acceptable & 7 & 3 & 0 & 3 \\
\hline & Fair & 2 & 2 & 6 & 3 \\
\hline & Poor & 2 & 14 & 8 & 8 \\
\hline \multirow{4}{*}{ Experimental Group } & Successful & 23 & 21 & 17 & 20 \\
\hline & Acceptable & 3 & 3 & 6 & 4 \\
\hline & Fair & 0 & 2 & 0 & 1 \\
\hline & Poor & 2 & 2 & 5 & 3 \\
\hline
\end{tabular}

The results of an independent-samples t-test (Table 4) demonstrated that the experimental group $(M=3.46, S D=0.99)$ outperformed the control group $(M=2.5, S D$ $=1.336), t(48)=-2.9, p=0.005$ in the post-test. This significant difference in terms of performance suggests that the implementation of WM strategies had indeed a positive effect on vocabulary retention among the students in the experimental group.

Table 4. T-test Results From Data Collected in Post-Test From Experimental and Control Groups

\begin{tabular}{|l|c|c|c|c|c|c|c|}
\hline \multicolumn{1}{|c|}{ Variable } & $\begin{array}{c}\text { Observa- } \\
\text { tions }\end{array}$ & $\begin{array}{c}\text { Obs. with } \\
\text { missing } \\
\text { data }\end{array}$ & $\begin{array}{c}\text { Obs. without } \\
\text { missing data }\end{array}$ & Minimum & Maximum & Mean & $S D$ \\
\hline Control & 22 & 0 & 22 & 1.000 & 4.000 & 2.500 & 1.336 \\
\hline Experimental & 28 & 0 & 28 & 1.000 & 4.000 & 3.464 & 0.999 \\
\hline
\end{tabular}

$t=-2.9206$

$d f=48$

$p$-value $=0.005309$ 


\section{Analysis and Discussion}

The results yielded in this study demonstrated that the set of strategies proposed by Gathercole and Alloway (2007) and others to activate the phonological loop can be beneficial for learners in terms of vocabulary learning. This fact was not only evident in the posttest, but also when the majority of participants from the experimental group was able to retrieve, recognize, use, and transfer the lexicon learned during the intervention strategies to other classroom tasks such as reading comprehension, oral discussions and participation, role plays, small debates and written compositions exercises, which took place during the course. In the first place, this finding may be accounted for by the hypothesis proposed by McNamara and Scott (2001), who state that an individual's WM problems may be due to lack of strategies to process information. It is possible that the participants in the experimental group were able to incorporate and transfer the training they received; thus, enhancing their WM and ultimately their overall performance in the target language.

On the other hand, the strategies implemented with the experimental group are consistent with those described by Chein and Morrison (2010). It could be that the nature of such tasks indeed helps learners to improve their performance in tasks requiring retention of information over time since their purpose is to reduce memory overload by encoding, repeating, and chunking information.

Conversely, it was seen that the experimental group also benefited from the strategies tackling the phonological loop. This result may be explained by the idea that activating the phonological loop increases the chances to store and retrieve vocabulary (Alharbi, 2015). Similarly, Engel de Abreu and Gathercole (2012) argue that providing learners with opportunities to store and rehearse auditory information may play a key role, especially at early stages of vocabulary learning, which is coherent with the participants of this study, that is, young adults taking an elementary English course.

\section{Conclusions}

In general terms, the results lead to suggest that WM training can certainly help minimize learners' memory limitations, thus increasing their vocabulary retention and retrieval capacity in the L2, which would ultimately result in better performance. Additionally, this targeted training may allow students to transfer the strategies learned to complete other tasks even when training is no longer taking place.

Concerning teaching implications, first, it is possible to affirm that as teachers, we need to be aware of the different factors that intervene in and may affect language learning, making it possible to come up with alternatives that could counteract any potential burdens or optimize the learning process. In this particular study, it was seen that both the control 
and experimental groups started out at basically the same level, but the group that received the intervention significantly outperformed the other, an outcome that may not have been achieved if no action had taken place. Therefore, the findings of this study invite other language teachers to reflect on their practice and strive to provide learners with the necessary tools to succeed in the learning process.

\section{Suggestions for Further Research}

This research intended to shed light on how certain WM strategies contribute to retain and retrieve vocabulary in English when implemented in the EFL classroom. Even though the results of this study demonstrated that the strategies are indeed beneficial, it would be appropriate to subsequently analyze how effective each individual strategy is by investigating students' response to each one of them.

Additionally, future research may look at how and to what extent strategies demanding learners to process auditory information can promote retention and retrieval of lexicon to be later applied in learning tasks requiring it.

Lastly, further studies may also be required in order to determine correlations among poor WM indicators (task engagement, attention span, procedure retention, and instruction understanding, among others) and overall language achievement.

\section{References}

Alharbi, A. H. (2015). Enhancing the phonological working memory capacity through classroombased instruction to develop EFL/ESL learning and teaching. International Journal of English Language Teaching, 3(3), 53-65.

Atkins, P. W. B., \& Baddeley, A. D. (1998). Working memory and distributed vocabulary learning. Applied Psycholinguistics, 19(4), 537-552. https://doi.org/10.1017/S0142716400010353.

Baddeley, A. D. (2000). The episodic buffer: A new component of working memory? Trends in Cognitive Sciences, 4(11), 417-423. https://doi.org/10.1016/S1364-6613(00)01538-2.

Baddeley, A. (2003). Working memory and language: An overview. Journal of Communication Disorders, 36(3), 189-208. https://doi.org/10.1016/S0021-9924(03)00019-4.

Baddeley, A., \& Hitch, G. (1974). Working memory. In G. H. Bower (Ed.), The psychology of learning and motivation (pp. 47-89). New York, US: Academic Press. https://doi.org/10.1016/S00797421(08)60452-1.

Cook, T. D., \& Campbell, D. T. (1979). Quasi-experimentation: Design and analysis issues for field settings. Boston, US: Houghton Mifflin. 
Chein, J. M., \& Morrison, A. B. (2010). Expanding the mind's workspace: Training and transfer effects with a complex working memory span task. Psychonomic Bulletin and Review, 17(2), 193199. https://doi.org/10.3758/PBR.17.2.193.

Daneman, M., \& Hannon, B. (2007). What do working memory span tasks like reading span really measure? In N. Osaka, R. Logie, \& M. D'Esposito (Eds.), The cognitive neuroscience of working memory (pp. 21-42). Oxford, UK: Oxford University Press. https://doi.org/10.1093/acprof: oso/9780198570394.003.0002.

Daneman, M., \& Merikle, P. M. (1996). Working memory and language comprehension: A metaanalysis. Psychonomic Bulletin and Review, 3(4), 422-433. https://doi.org/10.3758/BF03214546.

Ellis, N. C. (1996). Sequencing in SLA: Phonological memory, chunking and points of order. Studies in Second Language Acquisition, 18(1), 91-126. https://doi.org/10.1017/S0272263100014698.

Ellis, N. C. (2012). Formulaic language and second language acquisition: Zipf and the phrasal Teddy Bear. Annual Review of Applied Linguistics, 32, 17-44. https://doi.org/10.1017/ S0267190512000025.

Ellis, N. C. (2013). Construction grammar and second language acquisition. In T. Hoffmann \& G. Trousdale (Eds), Oxford handbook of construction grammar (pp. 365-378). Oxford, UK: Oxford University Press.

Ellis, N. C., \& Sinclair, S. G. (1996). Working memory in the acquisition of vocabulary and syntax: Putting language in good order. The Quarterly Journal of Experimental Psychology, 49(1), 234-250. https://doi.org/10.1080/713755604.

Engel de Abreu, P. M. J., \& Gathercole, S. E. (2012). Executive and phonological processes in second-language acquisition. Journal of Educational Psychology, 104(4), 974-986. https://doi. $\operatorname{org} / 10.1037 / \mathrm{a} 0028390$.

Engle, R. W., Kane, M. J., \& Tuholski, S. W. (1999). Individual differences in working memory capacity and what they tell us about controlled attention, general fluid intelligence, and functions of the prefrontal cortex. In A. Miyake \& P. Shah (Eds.), Models of working memory: Mechanisms of active maintenance and executive control (pp. 102-134). New York, US: Cambridge University Press. https://doi.org/10.1017/CBO9781139174909.007.

Gathercole, S. E., \& Alloway, T. P. (2007). Understanding working memory. A classroom guide. London, UK: Harcourt Assessment.

Harrington, M., \& Sawyer, M. (1992). L2 working memory capacity and L2 reading skills. Studies in Second Language Acquisition, 14(1), 25-38. https://doi.org/10.1017/S0272263100010457.

Holmes, J. (2012). Working memory and learning difficulties. Dyslexia Review, 23, 7-10.

Jarvis, P. (2006). Towards a comprehensive theory of human learning. London, UK: Routledge.

Kormos, J., \& Sáfár, A. (2008). Phonological short-term memory, working memory and foreign language performance in intensive language learning. Bilingualism: Language and Cognition, 11(2), 261-271. https://doi.org/10.1017/S1366728908003416.

Mackey, A., \& Gass, S. M. (2005). Second language research: Methodology and design. Mahwah, US: Lawrence Erlbaum. 
Martin, K. I., \& Ellis, N. C. (2012). The roles of phonological short-term memory and working memory in L2 grammar and vocabulary learning. Studies in Second Language Acquisition, 34(3), 379-413. https://doi.org/10.1017/S0272263112000125.

Martínez Ortega, D. (2016). How can working memory training enhance English vocabulary learning? (Master's thesis). Universidad ICESI, Cali, Colombia.

McNamara, D. S., \& Scott, J. L. (2001). Working memory capacity and strategy use. Memory and Cognition, 29(1), 10-17. https://doi.org/10.3758/BF03195736.

Service, E. (1992). Phonology, working memory, and foreign language learning. Quarterly Journal of Experimental Psychology, 45, 21-50. https://doi.org/10.1080/14640749208401314.

Shenfield, T. (2012, November 27). How to improve your working memory and attention [Web $\log$ post]. Retrieved from http://www.psy-ed.com/wpblog/working-memory-attention/.

\section{The Authors}

Diana Ibarra Santacruz holds a BA in English and French from Universidad de Nariño (Colombia) and an MA in English linguistics from Radboud University (The Netherlands). She belongs to the Language and Pedagogy research group at Universidad de Nariño. Her interests are second language acquisition, assessment, and methodology in language teaching.

David Martínez Ortega holds a BA in English and French from Universidad de Nariño (Colombia) and an MA in teaching English as a foreign language from Universidad ICESI (Colombia). His research interests include second language acquisition, alternative assessment, language teaching methodology, and autonomous learning. 


\section{Appendix: Implementation of the Working Memory Boosting Strategies (Gathercole \& Alloway, 2007)}

Strategy 1 . Reducing the memory load. The tasks consisted of a scrambled story. Students had to first fill in the blanks with the correct past forms of the verbs given in each part, then, they had to organize the story in a logical sequence. After that, they needed to provide a suitable title. Once the title was written, they were asked to write a similar narrative using the verbs studied before, and finally, they presented their product orally to the whole class and answered their peers' questions. The criteria for successful performance in this task were as follows:

1. Students are able to fill the gaps correctly.

2. Students can organize the correct sequence of the story.

3. Students are able to provide a logical and adequate title.

4. Students are able to come up with a similar narration using verbs studied.

5. Students are able to report their own story orally to the class.

Strategy 2. Triggering learners' retention by color code. The students were given some words (verbs in red and nouns in green) from the previous pre-test activity at the beginning. These words were printed out and cut individually for them to touch them and interact with them. Then, they had to match meanings/translation. Next, they memorized them by challenging their classmates about their meanings in English and Spanish.

The assessment criteria were as follows:

1. Students are able to match English-Spanish word pairs adequately.

2. Students can recognize and translate English words into Spanish while listening to them.

Strategy 3. Encouraging the use of memory aids. Students were required to create posters of words important for them and then write as many sentences as they could, including the word. They also had to include images or drawings.

The criteria for successful performance were:

1. Students are able to choose an appropriate word from the class to create their posters.

2. Students can come up with grammatically correct sentences using the word chosen.

3. Students are able to present their poster to the class with ease. 
Strategy 4. Reinforcing learning preferences. This strategy was implemented using Socrative and Kaboot, which are classroom technology-based techniques through which teachers can observe students' level of comprehension and understanding of a certain grammar component or any other class objective. First, learners used their mobiles to answer a series of questions, projected onto a large screen, based on the lesson and then they had to choose the correct answers. Later on in class, the teacher provided feedback to the whole class on the activity. The criterion for successful performance was:

1. Students are able to answer the questions posed correctly and give a brief grammatical explanation.

Strategy 5. Encouraging memory aids by clustering. The strategy sought to encourage students to make lists of reminders regularly by using graphic organizers while learning information and new concepts to retrieve them afterwards. They used boards to draw their clusters and explain them to the whole class.

The criteria for successful performance were as follows:

1. Students are able to make clusters using a word introduced and presented in class.

2. Students can relate the words to other expressions (word families).

Strategy 6. Introducing advance organizers. In this task, a "What I know, what I want to know, what I learned' (KWL) chart was used. It is a graphic organizer that helps students focus on what is to be learned. This tool activates prior knowledge, helps generate questions to explore, and then assists students to connect new knowledge to what they already know.

\section{Strategy 7. Fostering vocabulary retention by working on the phonological loop} I. In this task, students listened several times to a group of words without seeing them and without knowing their meaning trying to memorize as many as they could. Then, they were required to repeat them aloud. Next, the teacher handed over the words on pieces of paper and they had to organize them in the order that they had heard and check the meaning with the guidance of the teacher. Then, they were shown a set of pictures with which they had to match the words heard before. Finally, they were to describe a famous person/place by employing the words learned and the rest of the class tried to guess the person talked about. The criteria for successful performance in this task are as follows:

1. Students are able to match the words they hear to the equivalent image.

2. Students can include the words heard in an oral composition.

3. Students are able to give a short oral presentation of a person using the words they heard. 
Strategy 8 . Fostering vocabulary retention by working on the phonological loop II. In this task, students listened to a couple of physical features and basic clothing vocabulary to identify the character that is being described in the recording. A chart was projected onto a large screen so learners could carry it out properly. After this chart was filled, the students were required to come up with a description of a classmate without revealing his/her name so the rest of the class guessed that classmate. The criteria for successful performance in this task were:

1. Students are able to correctly match visual information with the information heard.

2. Students are able to describe a character by using the words previously introduced.

Strategy 9. Fostering vocabulary retention by working on the phonological loop III. This task consisted of giving learners a chart with some missing words. Then a recording with a sequence of three sentences was played so they could find the place where the missing words fit. Then another three sentences were played until they completed the whole chart. The criterion for successful performance in this task was:

1. Students are able to identify and complete the blanks with the sequence they heard previously.

Strategy 10. Fostering vocabulary retention by working on the phonological loop IV. As a follow-up activity of a certain lesson, learners practiced past tense through a bingo game by actively listening to the verbs called out by the teacher. In small groups, they were given several Call Cards with different present and past verbs to be recognized and covered as fast as possible. This task was intended to provide aural practice and make students more sensitive to speech-based information. 